\title{
Utilization of Nanocrystalline Cellulose for Adsorption of Divalent Cobalt Ions in the Aqueous Phase
}

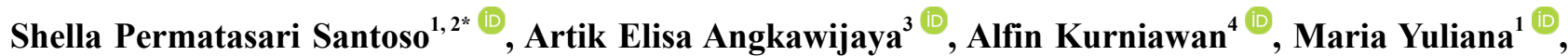 \\ Felycia Edi Soetaredjo $^{1,2}$, Suryadi Ismadji ${ }^{1,2}{ }^{\circledR}$, Hsien-Yi Hsu ${ }^{5,6}{ }^{\circledR}$, Phuong Lan Tran-Nguyen ${ }^{7}$, Yi- \\ Hsu $\mathrm{Ju}^{2,3,8}$
}

\begin{abstract}
${ }^{1}$ Department of Chemical Engineering, Widya Mandala Surabaya Catholic University, Surabaya 60114, Indonesia ${ }^{2}$ Department of Chemical Engineering, National Taiwan University of Science and Technology, Taipei 10607, Taiwan

${ }^{3}$ Graduate Institute of Applied Science and Technology, National Taiwan University of Science and Technology, Taipei 10607, Taiwan ${ }^{4}$ Department of Chemistry, National Sun Yat-Sen University, Kaohsiung 80424, Taiwan

${ }^{5}$ School of Energy and Environment \& Department of Materials Science and Engineering, City University of Hong Kong, Hong Kong, China ${ }^{6}$ Shenzhen Research Institute of City University of Hong Kong, Shenzhen, China

${ }^{7}$ Mechanical Engineering Department, Can Tho University, Can Tho 900100, Vietnam

${ }^{8}$ Taiwan Building Technology Center, National Taiwan University of Science and Technology, Taipei 10607, Taiwan

E-mail: shella_p5@yahoo.com, shella@ukwms.ac.id
\end{abstract}

Received: 1 September 2020; Revised: 17 October 2020; Accepted: 17 October 2020

\begin{abstract}
Nanocrystalline cellulose (NC) is a cellulose derivative product that has attracted a lot of attention because of its versatile applications, one of which is in adsorption. In this study, $\mathrm{NC}$ was prepared through $\mathrm{H}_{2} \mathrm{SO}_{4}$-hydrolysis of filter paper. Several physical characterizations were employed to confirm the formation of the NC nanoparticles, including scanning electron microscopy (SEM), transmission electron microscopy (TEM), X-ray diffraction (XRD) analysis, and Fourier transform infrared spectroscopy (FTIR). The nano-rod-shaped NC particles, with an average particle length of $255 \mathrm{~nm}$, were observed from the electron micrographs. The resemblance characteristic of NC with cellulose was demonstrated from the occurrence of XRD peaks at (110) and (200) lattice plane. The FTIR bands' spectra of the $\mathrm{NC}$ are similar to that of the reported literature. The $\mathrm{NC}$ was utilized as the adsorbent for the removal of cobalt ions in the synthetic solution. The effect of $\mathrm{pH}$ on the removal of cobalt ions by $\mathrm{NC}$ was evaluated by employing potentiometric titration. It was revealed that the complexation between the two compounds occurs greater at a $\mathrm{pH}$ of 6.6. The adsorption isotherm of cobalt ions was investigated at three different temperatures of 30,45 , and $60^{\circ} \mathrm{C}$. The adsorption isotherm was found to be well fitted with the Langmuir model, with the maximum adsorption capacity of $47.53 \mathrm{mg} \mathrm{g}^{-1}$ at $30^{\circ} \mathrm{C}$. The adsorption capacity was found to decline as the temperature increased, where the maximum adsorption capacity was $44.62 \pm 2.32$ and $40.56 \pm 2.03 \mathrm{mg} \mathrm{g}^{-1}$ at 45 and $60^{\circ} \mathrm{C}$, respectively. The adsorption of cobalt ions on $\mathrm{NC}$ shows the exothermic adsorption behavior.
\end{abstract}

Keywords: nanocrystalline cellulose, cellulose, potentiometric, adsorption, cobalt ions

\section{Introduction}

Several transition metals are known to be essential elements for all living organisms. Transition metals play an

Copyright (C2020 Shella Permatasari Santoso, et al.

DOI: https://doi.org/10.37256/fce.212021625

This is an open-access article distributed under a CC BY license

(Creative Commons Attribution 4.0 International License)

https://creativecommons.org/licenses/by/4.0/ 
important role in maintaining the functioning of some biological systems, and their deficiency can lead to various health problems. Cobalt (Co) is one of the essential elements; In metabolism, the source of Co mainly comes from vitamin $\mathrm{B}_{12}$ (cobalamin). Although the intake of $\mathrm{Co}$ in several different forms (other than vitamin $\mathrm{B}_{12}$ ) is possible, it is likely to cause abnormal action on biological functions. For example, Co, which is used as a stabilizing agent, reported causing heart toxicity. Concerns on Co poisoning are not prevalent in the past; But nowadays, concerns are starting to arise as the use of Co in various advanced technologies is increasing rapidly. ${ }^{1-2}$ Co has been broadly used in high technology (hitech) industries, such as in the production of artificial hips, dental prosthetics, turbines, and batteries. The emergence of the Co-based hi-tech industries plays a significant role in triggering Co contamination in waters, primarily through the disposal of Co-containing wastewater.

Co contamination in water can be one of the possible Co-poisoning routes. Separation of Co from water is not an easy task because Co can behave as an amphoteric compound. The amphotericity of Co causes it to readily-dissolve as oxides or hydroxides in water, increasing the likelihood of poisoning. ${ }^{3-5}$ The treatment of Co-containing water and wastewater can be a great solution to prevent Co-poisoning. Several physical and chemical methods are available to reduce or remove the amount of Co in water, such as ion exchange, precipitation, membrane filtration, electrochemical process, biosorption, and adsorption. Adsorption can be considered as an advantageous method compare to the other. The advantages of the adsorption method include the low operating cost, easy and fast operation, and environmentally friendly.

Nanocellulose (NC), also called nanocrystalline cellulose, is nano-sized cellulose, which can be obtained by shortening the linear cellulose chains through physical or chemical treatment. ${ }^{6} \mathrm{NC}$ has gained a lot of attention due to its excellent properties such as renewable, non-toxic, high crystallinity, high tensile strength, and unique fashion of dispersion. The potential adsorption ability of $\mathrm{NC}$ has been demonstrated in several studies. For example, Yu and the group reported that $\mathrm{NC}$ modified with succinic anhydride has maximum adsorption capacities of $367.6 \mathrm{mg} / \mathrm{g}(1.8 \mathrm{mmol} / \mathrm{g})$ on $\mathrm{Pb}^{2+}$ and $259.7 \mathrm{mg} / \mathrm{g}(2.3 \mathrm{mmol} / \mathrm{g})$ on $\mathrm{Cd}^{2+}{ }^{2}$ Voisin reported that unmodified NC could adsorb $\mathrm{Cu}^{2+}$ up to $47 \mathrm{mg} / \mathrm{g}(0.74$ $\mathrm{mmol} / \mathrm{g}) .{ }^{8}$ Putro and co-workers showed that $\mathrm{NC}$ has an adsorption capacity of $0.44 \mathrm{mmol} / \mathrm{g}(91.17 \mathrm{mg} / \mathrm{g})$ on $\mathrm{Pb}$ and 0.23 $\mathrm{mmol} / \mathrm{g}(46.14 \mathrm{mg} / \mathrm{g})$ on $\mathrm{Hg}{ }^{9}$

Although the prior studies have demonstrated the potential of $\mathrm{NC}$ as a metal adsorbent, however, there is yet a study investigating the adsorption capacity of $\mathrm{NC}$ against $\mathrm{Co}^{2+}$. This work presents the adsorption equilibrium study between $\mathrm{NC}$ and $\mathrm{Co}^{2+}$, which provide insight into their adsorption mechanism. In this study, the adsorption profile of $\mathrm{NC}$ against $\mathrm{Co}^{2+}$ was being investigated. The formation of $\mathrm{NC}$ was confirmed from an electron microscope micrograph. The characteristics of $\mathrm{NC}$ were analyzed using the X-ray diffraction (XRD) and Fourier transform infrared (FTIR) spectroscopy analysis. The $\mathrm{pH}$-potentiometric method was conducted to observe the $\mathrm{pH}$ at which the interaction of $\mathrm{NC}$ and $\mathrm{Co}^{2+}$ occurs. The adsorption equilibrium between $\mathrm{NC}$ and $\mathrm{Co}^{2+}$ was studied isothermally at three different temperatures. The results of this study can be useful for assisting the design of wastewater treatment, especially in managing Co contamination. Furthermore, this study shows a possible way to recycle Co from solution.

\section{Materials and methods}

\subsection{Materials}

Cobalt nitrate hexahydrate $\left(\mathrm{Co}\left(\mathrm{NO}_{3}\right)_{2} \cdot 6 \mathrm{H}_{2} \mathrm{O}, 98 \%\right.$ purity) was purchased from Sigma Aldrich (USA). Sulfuric acid $\left(\mathrm{H}_{2} \mathrm{SO}_{4}, 98 \%\right.$ purity) and hydrochloric acid ( $\mathrm{HCl}, 37 \%$ purity) were purchased from Sigma Aldrich (Germany). Sodium chloride ( $\mathrm{NaCl}, 99.5 \%$ purity) was obtained from Showa (Japan). Sodium hydroxide (NaOH, 96\% purity) was obtained from Yakuri Pure Chemical (Japan).

\subsection{Preparation of $\mathrm{NC}$}

$3 \mathrm{~g}$ of shredded filter paper (Whatman \# 1) was hydrolyzed in $100 \mathrm{~mL}$ of sulfuric acid solution (54\% v/v) at $45^{\circ} \mathrm{C}$ for 1 hour. A large amount (10 times from the initial volume) of cold distilled water was then added to stop the hydrolysis reaction. The reaction mixture is then left alone until the two layers of supernatant, and solid suspension are formed. The solid suspension is collected and placed in a dialysis bag, and then the dialysis bag is put into a container 
containing distilled water to remove excess acid. Distilled water is replaced repeatedly until the $\mathrm{pH}$ of the solution equal to the $\mathrm{pH}$ of the distilled water. Washed solid suspension, then sonicated for 30 minutes and frozen in the refrigerator at $-20^{\circ} \mathrm{C}$ overnight. The frozen NC suspension is then subject to a freeze dryer to get dry NC.

\subsection{Titrimetric analysis}

The titrimetric analysis was conducted to observe the effect of $\mathrm{pH}$ changes on the interaction between $\mathrm{NC}$ (adsorbent) and $\mathrm{Co}^{2+}$ (adsorbate). The investigation was carried out on the following solution systems, at a constant temperature of $25^{\circ} \mathrm{C}$ :

i. $0.003 \mathrm{~mol} \mathrm{~L}^{-1} \mathrm{HCl}$ solution $+0.2 \mathrm{wt} \% \mathrm{NC}$

ii. $0.003 \mathrm{~mol} \mathrm{~L}^{-1} \mathrm{HCl}$ solution $+0.003 \mathrm{~mol} \mathrm{~L}^{-1} \mathrm{Co}^{2+}$ salt solution $+0.2 \mathrm{wt} \% \mathrm{NC}$

iii. $0.003 \mathrm{~mol} \mathrm{~L}^{-1} \mathrm{HCl}$ solution $+0.003 \mathrm{~mol} \mathrm{~L}^{-1} \mathrm{Co}^{2+}$ salt solution $+0.4 \mathrm{wt} \% \mathrm{NC}$

The solutions were prepared in a $0.1 \mathrm{~mol} \mathrm{~L}^{-1} \mathrm{NaCl}$, with a total volume of $50 \mathrm{~mL}$. A standardized $\mathrm{NaOH}$ solution $\left( \pm 0.025 \mathrm{~mol} \mathrm{~L}^{-1}\right.$ in $\left.0.1 \mathrm{~mol} \mathrm{~L}^{-1} \mathrm{NaCl}\right)$ was used as titrant.

\subsection{Adsorption study}

Adsorption for $\mathrm{Co}^{2+}$ on $\mathrm{NC}$ was studied in batch mode. $1000 \mathrm{~mL}$ of $\mathrm{Co}^{2+}$ salt stock solution was prepared using a volumetric flask with an initial salt concentration of $500 \mathrm{mg} \mathrm{L}^{-1}\left(2.733 \mathrm{mmol} \mathrm{L}^{-1}\right)$. Subsequently, $50 \mathrm{~mL}$ of $\mathrm{Co}^{2+}$ solutions at several different diluted-concentration was prepared from the stock solution; specifically, 350, 300, 250, 200, 150, $100,75,50,20$, and $10 \mathrm{mg} \mathrm{L}^{-1}$. The solutions' $\mathrm{pH}$ was adjusted to a $\mathrm{pH}$ of 6.6 by adding a $0.1 \mathrm{~mol} \mathrm{~L}^{-1} \mathrm{NaOH}$ solution. The selection of $\mathrm{pH}$ is based on the investigation of $\mathrm{pH}$ effect on the $\mathrm{Co}^{2+}$ adsorption, where the highest $\mathrm{Co}^{2+}$ adsorption occurred at $\mathrm{pH}$ 6.6. Subsequently, $0.1 \mathrm{~g}$ of $\mathrm{NC}$ adsorbent was added into each flask. The adsorption was carried out in a shaking water bath with a thermostat for $24 \mathrm{~h}$ at $30^{\circ} \mathrm{C}$. The $\mathrm{NC}$ adsorbent was then separated by utilizing centrifugation at 13,000 rpm for $10 \mathrm{~min}$. The residual concentration of $\mathrm{Co}^{2+}$ was determined using an inductively coupled plasma atomic emission spectroscopy (ICP-AES). The equilibrium amount of $\mathrm{Co}^{2+}$ adsorbed $\left(q_{\mathrm{e}} / \mathrm{mg} \mathrm{g}^{-1}\right)$ was determined by using Eq. (1).

$$
q_{e}=\left(\frac{C_{0}-C_{f}}{m}\right) V
$$

where $C_{0}$ and $C_{f}$ are the initial and residual concentration of $\mathrm{Co}^{2+}$ in the solution with the unit of $\mathrm{mg} \mathrm{L}^{-1}, m$ is the specified gram of $\mathrm{NC}$ adsorbent, and $V$ is the total volume in $\mathrm{L}$. The batch adsorption study was also conducted at other temperature of 45 , and $60^{\circ} \mathrm{C}$.

\subsection{Characterization}

Several physicochemical analyses were done prior to characterizing the NC adsorbent. Scanning electron microscopy (SEM) techniques were used to observe the morphology of the NC particles using a JEOL JSM-6500F field emission electron microscope (Tokyo, Japan). Prior to the SEM imaging, the sample was coated with Pt-thin film using a JEOL auto fine coater JEC-3000FC. The SEM imaging was conducted at an accelerating volt of $5.0 \mathrm{kV}$. X-ray diffraction (XRD) technique using a Rigaku Miniflex Goniometer was employed to obtain the crystallinity pattern of the sample. Transmission electron microscopy (TEM) imaging was conducted using Tecnai F20 G2 FEI-TEM operated at $80 \mathrm{kV}$; the sample was stained using $2 \mathrm{wt} \%$ uranyl acetate and placed on a 300 mesh copper grid prior to the imaging. The particle length distribution of the sample was determined using an ImageJ 1.52a computer-software. The XRD pattern of the sample was collected in the range of $2 \theta$ of 10 to $40^{\circ}$ using the $\mathrm{CuK} \alpha$ radiation $(\lambda=1.5418 \AA)$ at $30 \mathrm{kV}$ and $10 \mathrm{~mA}$. The Fourier transform infrared spectroscopy (FTIR) analysis was performed using an FTIR Shimadzu $8400 \mathrm{~S}$. KBr powder was used as the background spectra, and the analysis was conducted at a wavenumber range of 4000 to $400 \mathrm{~cm}^{-1}$ with scanning speed of $128 \mathrm{~cm}^{-1} / \mathrm{scan}$. The titrimetric (pH-potentiometric) data were collected using a Metrohm 888 Titrando with an 805 Dosimat equipped with rod-stirrer, Ti stand, and Ecotrode Plus glass electrode. The data recording was performed using the titration software, Tiamo 2.3. 


\section{Results and discussion}

\subsection{Characterization of $\mathrm{NC}$}

The morphology of the NC was presented as the SEM image (Figure 1a), where the nano-rod shape of the particles is observed. Morphology observation using TEM imaging was conducted to clarify the particle shape and the average length distribution of NC. The nano-rod shape can be seen clearly from the TEM image in Figure 1b; the particles have an average length distribution of $255 \mathrm{~nm}$.

The XRD diffraction pattern of NC is presented in Figure 1c. The crystalline property of NC indicates by the appearance of the diffraction peak at $2 \theta$ of 15.5 and $22.6^{\circ}$, which corresponds to the lattice plane (110) and (200), respectively. ${ }^{10-11}$ The crystallinity index $(\mathrm{CI}, \%)$ of the $\mathrm{NC}$ can be calculated by employing the Segal equation: ${ }^{12}$

$$
\mathrm{CI}(\%)=\frac{I 200-I 110}{I 200} \times 100 \%
$$

where $I 200$ and $I 100$ are the measured intensity at the lattice plane (200) and (110), respectively. As calculated using Eq. (2), the $\mathrm{CI}$ of the $\mathrm{NC}$ particle is $61.7 \%$. The obtained CI was comparable to that of reported literature, i.e., within the range of 52.7 to $99.2 \%{ }^{10-11,13}$
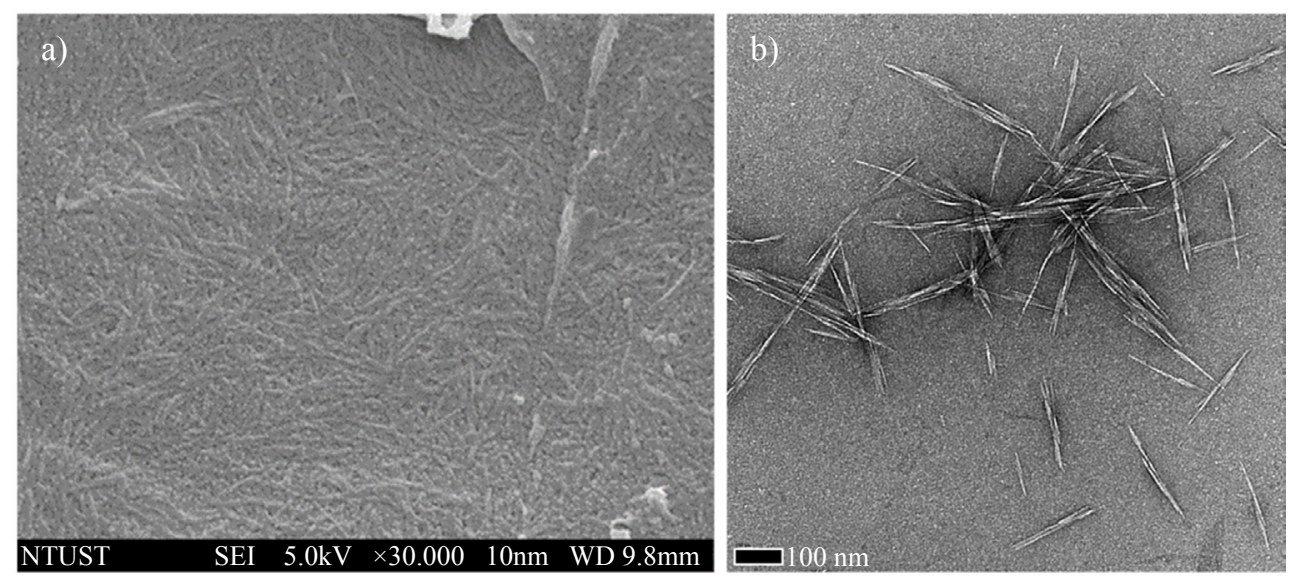

c)

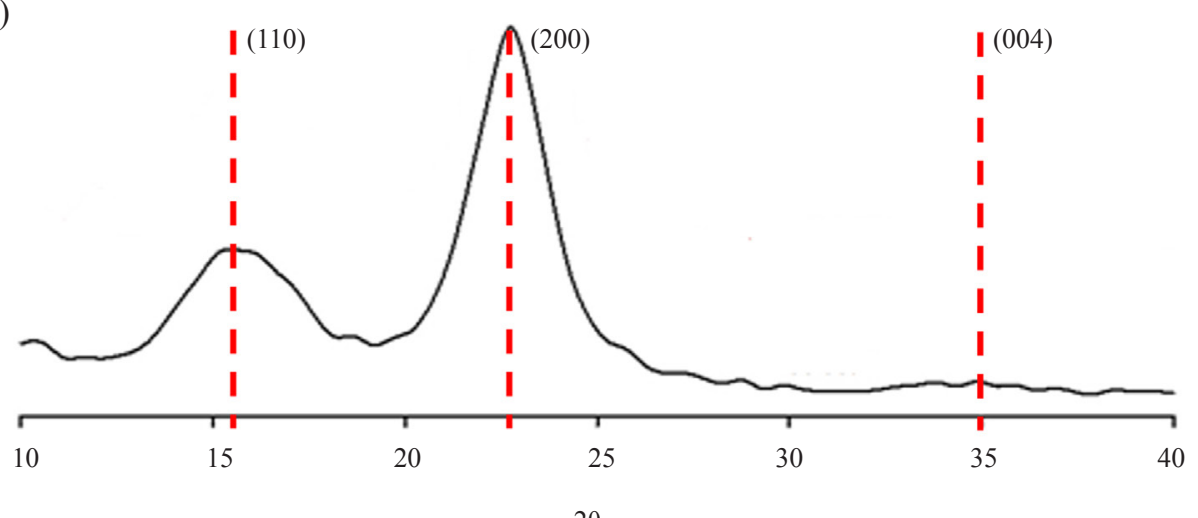

$2 \theta$

Figure 1. Characterization of the nanocrystalline cellulose (NC): (a) SEM at a magnification of 30,000×, (b) TEM images, and (c) XRD pattern

The FTIR spectra of the NC is summarized in Table 1; the FTIR of NC reported in other literature was also provided for comparison purposes. It was observed that the FTIR spectra of the NC sample are comparable with 
the different reported spectra. ${ }^{11,14-15}$ Specifically, the characteristic band corresponding to the -OH group stretching is observed at a wavenumber of $3300 \mathrm{~cm}^{-1}$. The bands observed at $2898,1645,1400$, and 1052 conform to the C-H stretching, $-\mathrm{OH}$ bending/ $\mathrm{C}=\mathrm{O}$ stretching, $\mathrm{C}-\mathrm{H}$ bending, and $\mathrm{C}-\mathrm{O} / \mathrm{C}-\mathrm{C}$ stretching, respectively.

Table 1. Selected FTIR peaks of nanocrystalline cellulose (NC)

\begin{tabular}{|c|c|c|c|c|}
\hline \multicolumn{4}{|c|}{ Wavenumber $\left(\mathrm{cm}^{-1}\right)$} & \multirow{2}{*}{ Assignment } \\
\hline \multirow[t]{2}{*}{ This work } & & Referenc & & \\
\hline & A & $\mathrm{B}$ & $\mathrm{C}$ & \\
\hline 3300 & 3313 & 3300 & $3100-3500$ & -OH stretching \\
\hline 2898 & 2895 & 2890 & $2800-2950$ & $\mathrm{C}-\mathrm{H}$ stretching \\
\hline 1645 & 1659 & 1630 & $1600-1650$ & $-\mathrm{OH}$ bending, $\mathrm{C}=\mathrm{O}$ stretching \\
\hline 1400 & 1427 & 1340 & $1400-1450$ & C-H bending \\
\hline 1052 & 1058 & 1050 & 1050 & C-O, C-C stretching \\
\hline
\end{tabular}

* Reference $\mathrm{A}=$ Santoso et al. ${ }^{14}$

Reference B $=$ Putro et al. ${ }^{11}$

Reference $\mathrm{C}=$ Evans et al. ${ }^{15}$

\subsection{Effect of $\mathrm{pH}$ in the adsorption of $\mathrm{Co}^{2+}$ on $\mathrm{NC}$}

The effect of $\mathrm{pH}$ in the removal of $\mathrm{Co}^{2+}$ ions from solution using $\mathrm{NC}$ adsorbent is presented in Figure 2a. The removal of $\mathrm{Co}^{2+}$ by $\mathrm{NC}$ increases as the solution $\mathrm{pH}$ becomes more alkaline. The removal of $\mathrm{Co}^{2+}$ continued to increase until a $\mathrm{pH}$ of 6 , then decreased with further $\mathrm{pH}$ increases. The effect of $\mathrm{pH}$ in the decrease or increase of the $\mathrm{Co}^{2+}$ removal can be further investigated by employing the potentiometric titration method. The titration profile resulting from the potentiometric method can show the $\mathrm{pH}$ at which the surface charge of $\mathrm{NC}$ changes; that is, by evaluating the occurrence of the equivalence point. Since NC is a weak organic acid, the appearance of the equivalence point indicates the $\mathrm{pH}$ at which the surface charge of $\mathrm{NC}$ will become more negative. ${ }^{16-18}$ The negative surface charge results from the deprotonation of the dissociable groups in $\mathrm{NC}$, in this case, the hydroxyl (-OH) groups.

The titration profiles of the system containing $\mathrm{Co}^{2+}$ and $\mathrm{NC}$ are presented in Figure $2 \mathrm{~b}$. In the system comprising $\mathrm{NC}$ only (the black circle dots), the first equivalence point of $\mathrm{NC}$ was observed at $\mathrm{pH} \sim 4.3$. This indicates the beginning of the deprotonation of $\mathrm{NC}$, which causes a negative surface charge. As the $\mathrm{pH}$ is increased, the second equivalence point was observed at near $\mathrm{pH} 7.5$-suggesting further deprotonation of the other dissociable groups of NC. The deprotonation behavior of $\mathrm{NC}$ can be correlated to the low $\mathrm{Co}^{2+}$ removal at low (acidic) $\mathrm{pH}$. $\mathrm{NC}$ particles tend to be positively charged at low $\mathrm{pH}$, and therefore there will be a repulsion interaction with $\mathrm{Co}^{2+}$, which is also positively charged.

The interaction profile of systems containing both $\mathrm{NC}$ and $\mathrm{Co}^{2+}$ were also evaluated. In a system comprising an organic acid and metal ions, an equivalence point signifies the $\mathrm{pH}$ at which complexation-interaction between the organic acid and metal ions occurs. ${ }^{16-18}$ The presence of metal ions can interrupt the H-bond of the organic acid, and thus, the deprotonation of $\mathrm{NC}$ occurs at lower $\mathrm{pH}$. As can be observed from the titration profile of the system containing $0.2 \mathrm{wt} \% \mathrm{NC}$ and $\mathrm{Co}^{2+}$ (the red triangle-down dots), the second equivalence point of the system occurs at $\mathrm{pH} \sim 6.0$-This can be attributed to the interaction between $\mathrm{Co}^{2+}$ and $\mathrm{NC}$, which support the adsorption of $\mathrm{Co}^{2+}$. In the system containing $0.4 \mathrm{wt} \% \mathrm{NC}$ and $\mathrm{Co}^{2+}$ (the green square dots), the second equivalence point appears at slightly higher $\mathrm{pH}(\sim 6.1)$; this is since the $\mathrm{H}$-bond disruption by $\mathrm{Co}^{2+}$ is delayed due to the larger amount of $\mathrm{NC}$ particles. The first equivalence point for all systems containing $\mathrm{NC}$ and $\mathrm{Co}^{2+}$ is found at a similar $\mathrm{pH}$ to that of the system comprising $\mathrm{NC}$ only, suggesting that no complexation occurs at this point. ${ }^{14,17-18}$ This is since both $\mathrm{NC}$ and $\mathrm{Co}^{2+}$ are positively charged; thus repulsion interaction occurs instead of complexation. The results and analysis of the titration profile of $\mathrm{NC}$ and $\mathrm{Co}^{2+}$ system can be well-correlated to the high removal of $\mathrm{Co}^{2+}$ at a $\mathrm{pH}$ of 6 . The interaction between $\mathrm{NC}$ and $\mathrm{Co}^{2+}$ can be proposed as follows: 


$$
\begin{gathered}
\mathrm{R}-\mathrm{OH}_{2}^{+} \leftrightarrow \mathrm{R}-\mathrm{OH}+\mathrm{H}^{+} \\
\mathrm{R}-\mathrm{OH} \leftrightarrow \mathrm{R}-\mathrm{O}^{-}+\mathrm{H}^{+} \\
\mathrm{R}-\mathrm{O}^{-}+\mathrm{Co}^{2+} \leftrightarrow \mathrm{R}-\mathrm{OCo}^{+}
\end{gathered}
$$

where $\mathrm{R}$ represents the adsorbent surface; $\mathrm{R}-\mathrm{OH}_{2}^{+}, \mathrm{R}-\mathrm{OH}$ and $\mathrm{R}-\mathrm{O}^{-}$represent the protonated, first deprotonated, and second deprotonated surface groups of the adsorbent; $\mathrm{R}-\mathrm{OCo}^{+}$represent the formed complex species.

Another equivalence point at $\mathrm{pH}>7$ can be observed for all systems containing $\mathrm{NC}$ and $\mathrm{Co}^{2+}$. The occurrence of the equivalence point at this $\mathrm{pH}$ can be attributed to the formation of neutral and negative-charged hydroxide species of Co. As reported by El-Deen, the $\mathrm{Co}(\mathrm{OH})_{2}$ and $\mathrm{Co}(\mathrm{OH})_{3}{ }^{-}$species start to occur at $\mathrm{pH} \sim 7.5 .^{19}$ As observed in Figure $2 \mathrm{a}$, there is a significant decrease in the removal of $\mathrm{Co}^{2+}$ at $\mathrm{pH}>7$; this indicates that the complexation interaction is declining.
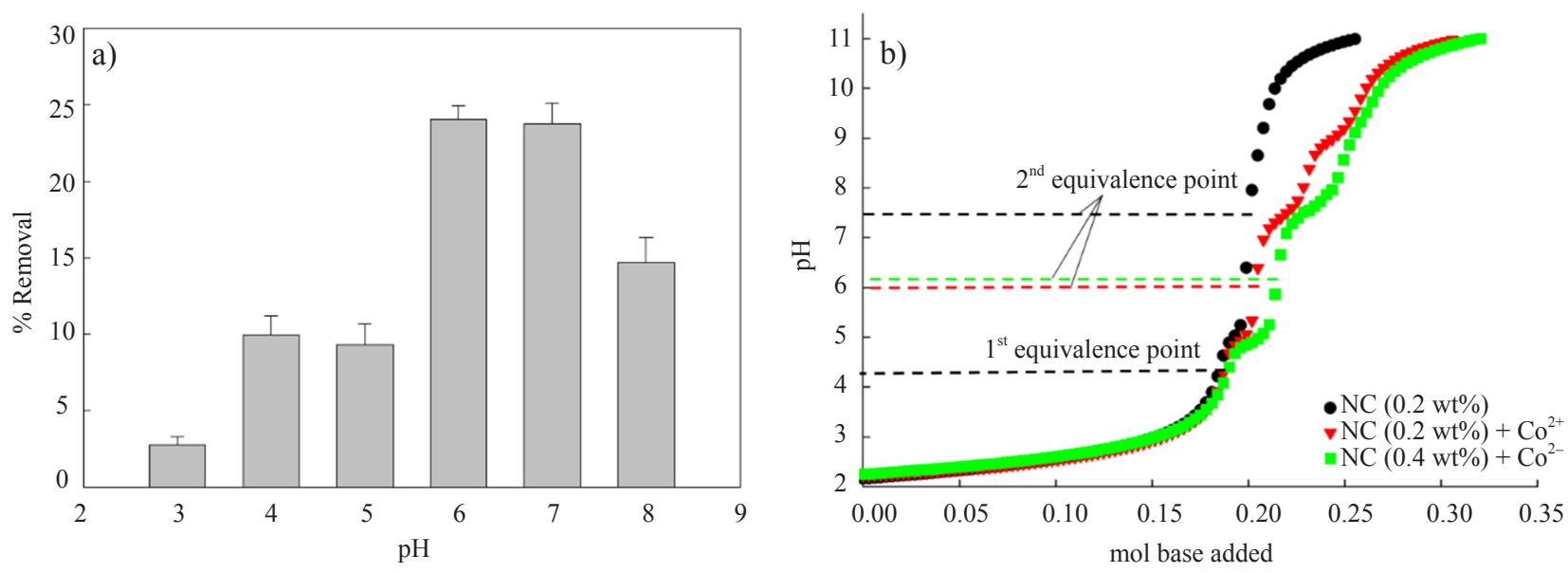

Figure 2. (a) Effect of $\mathrm{pH}$ on the removal of $\mathrm{Co}^{2+}$ using $\mathrm{NC}$ adsorbent.
(b) The titration curve of $\mathrm{Co}^{2+}, \mathrm{NC}$, and $\mathrm{NC}+\mathrm{Co}^{2+}$ systems in the aqueous phase in the presence of $I=0.1 \mathrm{~mol} \mathrm{~L}^{-1} \mathrm{NaCl}$ at $298 \mathrm{~K}$

A more careful investigation of the effect of $\mathrm{pH}$ on the removal of $\mathrm{Co}^{2+}$ by $\mathrm{NC}$ was conducted at $\mathrm{pH}$ between 6 and 7 ; since the highest removal of $\mathrm{Co}^{2+}$ was found around this $\mathrm{pH}$ (Figure 2a). As shown in Figure 3, the value of the removal of $\mathrm{Co}^{2+}$ in the $\mathrm{pH}$ range between 6-7 is slightly different. The removal of $\mathrm{Co}^{2+}$ appears to be marginally higher at a pH of 6.6, and therefore, the later adsorption study was conducted at this $\mathrm{pH}$. 


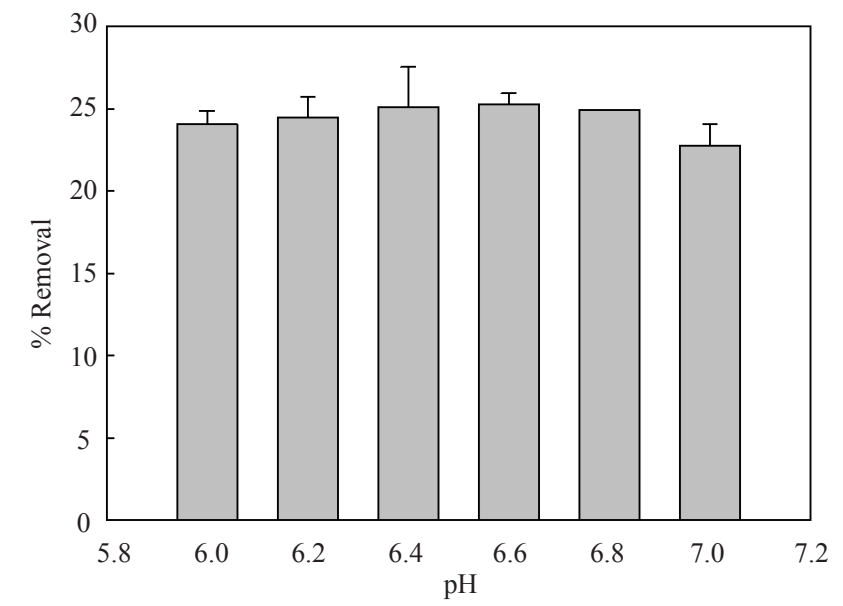

Figure 3. Removal profile of $\mathrm{Co}^{2+}$ by $\mathrm{NC}$ adsorbent at $\mathrm{pH}$ between 6.0 to 7.0

\subsection{Isotherm adsorption study}

The adsorption isotherm profile can be described by observing the concentration of the adsorbate in equilibrium, $C_{e}\left(\mathrm{mg} \mathrm{L}^{-1}\right)$, and the amount of adsorbate adsorbed on adsorbent in equilibrium, $q_{e}\left(\mathrm{mg} \mathrm{g}^{-1}\right)$. The correlation between the two equilibrium parameters can be modeled using isotherm models such as Langmuir, Freundlich, Redlich-Peterson, and Temkin. ${ }^{20-23}$ Langmuir is a classic isotherm model that deals with monolayer coverage of adsorbate on the adsorbent surface. In the term of metal $\left(\mathrm{Co}^{2+}\right)$ and organic compound $(\mathrm{NC})$, the monolayer can be described as a stoichiometry formation of 1:1 complex ( $1 \mathrm{~mol} \mathrm{Co}{ }^{2+}$ as adsorbate ion and $1 \mathrm{~mol}$ of $\mathrm{NC}$ as the sorption site). The occupancy of adsorbate ions on the surface adsorption sites of adsorbent is described as the Langmuir equilibrium constant, $K_{L}\left(\mathrm{~L} \mathrm{mg}^{-1}\right)$. The Langmuir isotherm model can be described as Eq. 6.

$$
q_{e}=q_{\max } \frac{K_{L} C_{e}}{1+K_{L} C_{e}}
$$

where $Q_{\max }\left(\mathrm{mg} \mathrm{g}^{-1}\right)$ is the maximum capacity of the adsorbate that can bond to the surface of the adsorbent in the form of the monolayer. The favorability of monolayer adsorption in the Langmuir model can be judged by the dimensionless favorability constant, $R_{L}$, which is expressed as Eq. 7 .

$$
R_{L}=\frac{1}{1+K_{L} C_{0}}
$$

The parameter $C_{0}\left(\mathrm{mg} \mathrm{L}^{-1}\right)$ is the initial concentration of the adsorbate. The value of $R_{L}>1$ signifies unfavorable monolayer adsorption, $R_{L}=1$ signifies linear adsorption, $R_{L}=0$ indicates irreversible adsorption, while a value between 0 to 1 shows a favorable process.

Freundlich is the isotherm model that can describe the multisite adsorption on the rough surface of the adsorbent; it is the most widely used model to describe the nonideal sorption process. Freundlich model includes two fitting parameters of the adsorption capacity, $K_{F}\left(\mathrm{mg} \mathrm{g}^{-1}\right)$ and a dimensionless constant $n$, which describes the intensity of adsorption. The value of can be directly related to the adsorption process, in which if the value falls between 0 to 1 , it indicates chemisorption while a value above 1 indicates cooperative adsorption. The $\alpha$ value close to 1 indicates the more homogenous surface of the adsorbent. The Freundlich model can be expressed as Eq. 8.

$$
q_{e}=K_{F} C_{e}^{\alpha}
$$


Redlich-Peterson (R-P) isotherm is a new model hybrid from the Langmuir and Freundlich models. ${ }^{24}$ The R-P isotherm provides compensation on the inaccuracies from the two pioneer models. The R-P model introduces three fitting parameters of $q_{\max }\left(\mathrm{mg} \mathrm{g}^{-1}\right)$ which describe the adsorption capacity, $b_{R-P}\left(\mathrm{~L} \mathrm{~g}^{-1}\right)$ is the volume of the adsorbent occupied by the adsorbate, and $\alpha$ is the adsorption intensity as in Freundlich model. The R-P isotherm can be expressed as Eq. 9.

$$
q_{e}=q_{\max } \frac{b_{R-P} C_{e}}{1+b_{R-P} C_{e}^{\alpha}}
$$

If the adsorption system is close to ideal monolayer adsorption, the $\alpha$ value is close to 1 , and the model will have the same form as the Langmuir model. When the adsorption system is not an ideal monolayer, the value of $1 / b_{R-P} q_{\max }$ close to 0 , the model will have the same form as the Freundlich model.

Temkin isotherm can provide information about the interaction between the adsorbate and adsorbent and the binding energy involved in the adsorption. The Temkin model is used to describe the binding energy of the homogenous adsorbent's surface. This model assumed that the heat in the adsorption process is decreased linearly as the adsorbate coverage becomes more spreading. The Temkin model is expressed as Eq. 10.

$$
q_{e}=\frac{R T}{b_{T}} \operatorname{In} A_{T}+\frac{R T}{b_{T}} \operatorname{In} C_{e}
$$

where $R\left(\mathrm{~J} \mathrm{~mol}^{-1} \mathrm{~K}^{-1}\right)$ is the ideal gas constant, and $T(\mathrm{~K})$ is the adsorption temperature. The parameter $A_{T}\left(\mathrm{~L} \mathrm{~g}^{-1}\right)$ represents the Temkin equilibrium binding constant and $b_{T}$ is a constant that represents the Temkin constant related to the heat energy $\left(\mathrm{J} \mathrm{mol}^{-1}\right)$.

The equilibrium adsorption data for the adsorption of $\mathrm{Co}^{2+}$ onto $\mathrm{NC}$ is given in Figure 4. The adsorption isotherm data can be categorized into an $L$-class curve with subclass 2, according to classification by Giles et al. (1960). This indicates that the adsorbate ions are adsorbed flat on the surface of the adsorbent and that van der Waals forces occur in the adsorption process. ${ }^{25}$ It can also be observed that the equilibrium adsorption capacity $\left(q_{\mathrm{e}}\right)$ decreases with the increase of temperature, indicating the exothermic behavior of the adsorption process. 

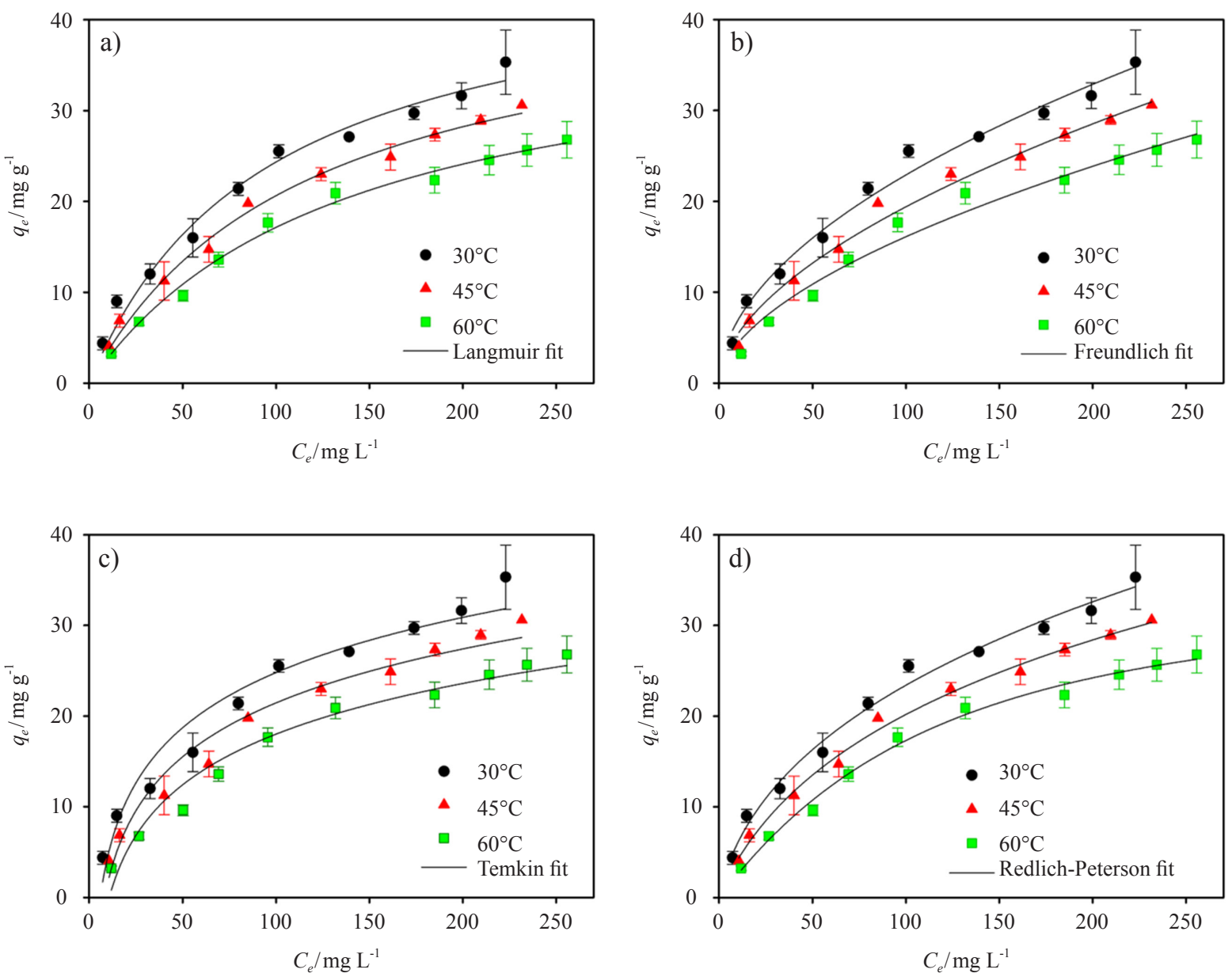

Figure 4. Adsorption isotherm data for $\mathrm{Co}^{2+}$ adsorption using $\mathrm{NC}$ adsorbent, and the model fittings: (a) Langmuir model, (b) Freundlich model, (c) Redlich-Peterson, and (d) Temkin model

The fitting of adsorption data with the isotherm models (Langmuir, Freundlich, Redlich-Peterson, and Temkin) is given in Figure $4 \mathrm{a}$ to d, and the calculated fitting parameters are presented in Table 2. The fitting models of Langmuir and Freundlich result in a high value of $r^{2}$. Furthermore, the fitting models result in a similar value of SS error. This indicates the goodness-of-fitting between the data and the proposed models. Since all the fitting models can well represent the equilibrium data, it is tricky to determine the most suitable model for the adsorption system. Therefore, the analysis for each parameter in the models should be conducted to determine the suitability of the model. ${ }^{16,26}$ Based on the Langmuir model, the adsorption can be considered as a favorable process since the $R_{L}$ value falls between 0 to 1. The $\alpha$ value in the Freundlich parameter, close to 1 , indicates that the adsorbent possesses a homogeneous surface. The tendency of the adsorption process to better approach the Langmuir or Freundlich model can be assessed using the Redlich-Peterson model. The $\alpha$ value in the Redlich-Peterson model, which is close to 1 , is an indication of the Langmuir model approach rather than the Freundlich model. The last model, Temkin, can be used to evaluate the adsorption energy. The negative value of $R T / b_{T}$ shows that the adsorption is an exothermic process, which is consistent with the isotherm data. 
Table 2. The fitting parameters for the adsorption of $\mathrm{Co}^{2+}$ on $\mathrm{NC}$ at various temperatures

\begin{tabular}{|c|c|c|c|c|}
\hline \multirow{2}{*}{ Model } & \multirow{2}{*}{ Unit } & \multicolumn{3}{|c|}{ Temperature } \\
\hline & & $30^{\circ} \mathrm{C}$ & $45^{\circ} \mathrm{C}$ & $60^{\circ} \mathrm{C}$ \\
\hline \multicolumn{5}{|l|}{ Langmuir } \\
\hline$Q_{\max }$ & $\mathrm{mg} \mathrm{g}^{-1}$ & $47.53 \pm 3.39$ & $44.62 \pm 2.32$ & $40.56 \pm 2.03$ \\
\hline$K_{L}$ & $\mathrm{~L} \mathrm{mg}^{-1}$ & $0.02 \pm 0.01$ & $0.01 \pm 0.00$ & $0.01 \pm 0.00$ \\
\hline$R_{L}$ & & $0.16 \pm 0.02$ & $0.19 \pm 0.02$ & $0.22 \pm 0.00$ \\
\hline$r^{2 \dagger}$ & & 0.98 & 0.99 & 0.99 \\
\hline $\mathrm{SS}_{*}^{*}$ & & 17.93 & 6.16 & 4.53 \\
\hline P-value ${ }^{\S}$ & & 0.46 & 0.57 & 0.1 \\
\hline \multicolumn{5}{|l|}{ Freundlich } \\
\hline$K_{F}$ & $\left(\mathrm{mg} \mathrm{g}^{-1}\right)\left(\mathrm{mg} \mathrm{L}^{-1}\right)^{-\alpha}$ & $2.07 \pm 0.30$ & $1.40 \pm 0.22$ & $1.18 \pm 0.26$ \\
\hline$\alpha$ & & $0.82 \pm 0.03$ & $0.87 \pm 0.03$ & $0.87 \pm 0.04$ \\
\hline$r^{2 \dagger}$ & & 0.99 & 0.99 & 0.97 \\
\hline $\mathrm{SS}_{*}^{*}$ & & 13.07 & 9.05 & 14.55 \\
\hline P-value ${ }^{s}$ & & 0.28 & 0.09 & 0.16 \\
\hline \multicolumn{5}{|l|}{ R-P } \\
\hline$Q_{\max }$ & $\mathrm{mg} \mathrm{g}^{-1}$ & $52.35 \pm 2.82$ & $47.25 \pm 3.54$ & $41.27 \pm 4.00$ \\
\hline$b_{R-P}$ & $\mathrm{~L} \mathrm{~g}^{-1}$ & $0.02 \pm 0.00$ & $0.03 \pm 0.01$ & $0.03 \pm 0.00$ \\
\hline$\alpha$ & & $0.82 \pm 0.12$ & $0.89 \pm 0.13$ & $1.01 \pm 0.24$ \\
\hline$r^{2 \dagger}$ & & 0.99 & 0.99 & 0.99 \\
\hline $\mathrm{SS}_{*}^{*}$ & & 10.58 & 4.49 & 4.42 \\
\hline P-value ${ }^{\S}$ & & 0.23 & 0.94 & 0.16 \\
\hline \multicolumn{5}{|l|}{ Temkin } \\
\hline$R T / b_{T}$ & $\left(\mathrm{~kJ} \mathrm{~g}^{-1}\right) \mathrm{Mw}$ & $-15.63 \pm 2.98$ & $-18.07 \pm 2.40$ & $-19.13 \pm 2.35$ \\
\hline$A_{T}$ & $\mathrm{~L} \mathrm{~g}^{-1}$ & $0.17 \pm 0.06$ & $0.12 \pm 0.05$ & $0.09 \pm 0.01$ \\
\hline$r^{2 \dagger}$ & & 0.95 & 0.97 & 0.97 \\
\hline $\mathrm{SS}_{*}^{*}$ & & 45.58 & 24.55 & 19.30 \\
\hline P-value ${ }^{s}$ & & 0.89 & 0.35 & 0.97 \\
\hline
\end{tabular}

$r^{2}=$ r-squared value, showing the goodness-of-fitting of the data

* $\mathrm{SS}=$ Sum of squares, showing the deviation between the predicted and actual data

${ }^{\S} \mathrm{P}$-value obtained using the Shapiro-Wilk test with $\alpha=0.05$. P-value $>0.05$ shows that the null hypothesis is not rejected

\subsection{Comparison study}

As can be assessed from Table 3, the maximum adsorption capacity of $\mathrm{NC}$ against $\mathrm{Co}^{2+}$ is comparable to those other adsorbents derived from biomass. Also, it is worth to mention that NC (this work) has higher adsorption capacity compared to some adsorbent, i.e., dried Rhytidiadelphus squarrosus $(7.25 \mathrm{mg} / \mathrm{g})$, activated carbon from hazelnut shell $(13.88 \mathrm{mg} / \mathrm{g})$, alkali modified rice straw $(32.3 \mathrm{mg} / \mathrm{g})$, sepiolite $(4.72 \mathrm{mg} / \mathrm{g})$, and palygorskite $(8.88 \mathrm{mg} / \mathrm{g})$. The physisorption and chemisorption tendency of the adsorption depends on the type of adsorbent.

Table 3. The maximum adsorption capacity of cobalt on some biomass-derived adsorbents

\begin{tabular}{|c|c|c|c|c|}
\hline Adsorbent & Characteristic & Temp. (K) & $\mathrm{Q}_{\max }\left(\mathrm{mg} \mathrm{g}^{-1}\right)$ & Ref. \\
\hline Sepiolite & Physisorption & 293 & 4.72 & 27 \\
\hline Palygorskite & Chemisorption & 308 & 8.88 & 28 \\
\hline Almond green hull & n. a. & 298 & 45.5 & 29 \\
\hline Raw rice straw & Chemisorption & 301 & 28.5 & 30 \\
\hline Alkali modified rice straw & Chemisorption & 301 & 32.3 & 30 \\
\hline Activated carbon from hazelnut shell & Chemisorption & 303 & 13.88 & 31 \\
\hline Dried Rhytidiadelphus squarrosus & n. a. & 293 & 7.25 & 32 \\
\hline Lignocellulose-montmorillonite composite & Physisorption & 351 & 91.6 & 33 \\
\hline Nanocrystalline cellulose & Chemisorption & $\begin{array}{l}303 \\
318 \\
333\end{array}$ & $\begin{array}{l}47.5 \\
44.6 \\
40.6\end{array}$ & This work \\
\hline
\end{tabular}




\section{Conclusion}

The nano-rod-shaped nanocrystalline cellulose (NC) with an average particle length of $255 \mathrm{~nm}$ and a crystallinity index of $61.7 \%$ was successfully prepared through acid hydrolysis of filter paper. The study demonstrates the potential of $\mathrm{NC}$ as an adsorbent to remove cobalt ions from aqueous solutions through the adsorption process. The results shown in this study can be useful for designing the adsorption system for water and wastewater treatment. NC possesses hydroxyl-containing surface functional groups which actively bind the free cobalt ions in solution. The removal of cobalt ions occurred better at a $\mathrm{pH}$ of 6.6, where the deprotonation of surface functional groups of $\mathrm{NC}$ occurs. The adsorptive interaction between $\mathrm{NC}$ and cobalt ions occurs due to electrostatic forces that arise due to the difference in charge between them. The adsorption of cobalt ions onto NC proceeds exothermically, where the adsorption capacity declines as the temperature increases.

\section{Acknowledgment}

The authors gratefully acknowledge the funding from Widya Mandala Catholic University through the Internal Research Grant.

\section{References}

[1] Titcomb, T. J.; Tanumihardjo, S. A. Compr. Rev. Food Sci. F. 2019, 18, 1968-1984.

[2] Rizzo, G.; Laganà, A. S.; Rapisarda, A. M. C.; Ferrera, G. M. G. L.; Buscema, M.; Rossetti, P.; Nigro, A.; Muscia, V.; Valenti, G.; Sapia, F.; Sarpietro, G.; Zigarelli, M.; Vitale, S. G. Nutrients 2016, 8, 767.

[3] Ghosh, S.; Abanteriba, S. Sci. Technol. Adv. Mater. 2016, 17, 715-735.

[4] Eliaz, N. Materials (Basel) 2019, 12, 407.

[5] Palansooriya, K. N.; Shaheen, S. M.; Chen, S. S.; Tsang, D. C. W.; Hashimoto, Y.; Hou, D.; Bolan, N. S.; Rinklebe, J.; Ok, Y. S. Environ. Int. 2020, 134, 1-29.

[6] Abitbol, T.; Rivkin, A.; Cao, Y.; Nevo, Y.; Abraham, E.; Ben-Shalom, T.; Lapidot, S.; Shoseyov, O. Curr. Opin. Biotechnol. 2016, 39, 76-88.

[7] Yu, X.; Tong, S.; Ge, M.; Wu, L.; Zuo, J.; Cao, C.; Song, W. J. Environ. Sci. 2013, 25, 933-943.

[8] Voisin, H.; Bergstrom, L.; Liu, P.; Mathew, A. P. Nanomaterials (Basel) 2017, 7, 57.

[9] Putro, J. N.; Santoso, S. P.; Ismadji, S.; Ju, Y.-H. Micropor. Mesopor. Mater. 2017, 246, 166-177.

[10] Ditzel, F. I.; Prestes, E.; Carvalho, B. M.; Demiate, I. M.; Pinheiro, L. A. Carbohydr. Polym. 2017, 157, 1577-1585.

[11] Putro, J. N.; Ismadji, S.; Gunarto, C.; Yuliana, M.; Santoso, S. P.; Soetaredjo, F. E.; Ju, Y. H. J. Mol. Liq. 2019, 282, 407-414.

[12] Segal, L.; Creely, J. J.; Martin, A. E.; Conrad, C. M. Tex. Res. 1962, 29, 786-794.

[13] Abiaziem, C. V.; Williams, A. B.; Inegbenebor, A. I.; Onwordi, C. T.; EhiEromosele, C. O.; Petrik, L. F. IOP Conf. Series: Journal of Physics 2019, 1299, 1-9.

[14] Santoso, S. P.; Laysandra, L.; Putro, J. N.; Lie, J.; Soetaredjo, F. E.; Ismadji, S.; Ayucitra, A.; Ju, Y. H. J. Mol. Liq. 2017, 233, 29-37.

[15] Evans, S. K.; Wesley, O. N.; Nathan, O.; Moloto, M. J. Heliyon 2019, 5, 1-7.

[16] Tran, H. N.; You, S.-J.; Hosseini-Bandegharaei, A.; Chao, H.-P. Water Res. 2017, 120, 88-116.

[17] Ben-Ali, S.; Jaouali, I.; Souissi-Najar, S.; Ouederni, A. J. Clean. Prod. 2017, 142, 3809-3821.

[18] Trojanowicz, A. H. M. Talanta 1969, 16, 225-234.

[19] El-Deen, G. E. S.; Imam, N. G.; Ayoub, R. R. Radiochim. Acta 2016, 105, 141-159.

[20] Langmuir, I. J. Am. Chem. Soc. 1916, 38, 2221-2295.

[21] Freundlich, H. Trans. Faraday Soc. 1932, 28, 195-201.

[22] Al-Ghouti, M. A.; A.Da'ana, D. J. Hazard. Mater. 2020, 393, 122383.

[23] Ayawei, N.; Ebelegi, A. N.; Wankasi, D. J. Chem. 2017, 2017, 3039817.

[24] Wu, F.-C.; Liu, B.-L.; Wu, K.-T.; Tseng, R.-L. Chem. Eng. J. 2010, 162, 21-27.

[25] Piccin, J. S.; Cadaval, T. R. S. A.; Pinto, L. A. A. d.; Dotto, G. L. Adsorption Isotherms in Liquid Phase: Experimental, Modeling, and Interpretations. In Adsorption Processes for Water Treatment and Purification; 
Bonilla-Petriciolet, A.; Mendoza-Castillo, D. I.; Reynel-Ávila, H. E., Ed.; Springer: Berlin, 2017; pp 19-51.

[26] Febrianto, J.; Kosasih, A. N.; Sunarso, J.; Ju, Y. H.; Indraswati, N.; Ismadji, S. J. Hazard. Mater. 2009, 162, 616645.

[27] Kara, M.; Yuzer, H.; Sabah, E.; Celik, M. S. Water Res. 2003, 37, 224-232.

[28] He, M.; Zhu, Y.; Yang, Y.; Han, B.; Zhang, Y. Appl. Clay Sci. 2011, 54, 292-296.

[29] Ahmadpour, A.; Tahmasbi, M.; Bastami, T. R.; Besharati, J. A. J. Hazard. Mater. 2009, 166, 925-930.

[30] Swelam, A. A.; Awad, M. B.; Salem, A. M. A.; El-Feky, A. S. HRBC Journal 2016, (In Press).

[31] Demirbas, E. Adsorp. Sci. Technol. 2003, 21, 951-963.

[32] Maresova, J.; Pipiska, M.; Rozloznik, M.; Hornik, M.; Remenarova, L.; Augustin, J. Desalination 2011, $266,134-$ 141.

[33] Zhang, X.; Wang, X.; Chen, Z. Int. J. Environ. Res. Public Health 2017, 14, 1453. 